Check for updates

Cite this: RSC Adv., 2019, 9, 36967

Received 20th September 2019

Accepted 21st October 2019

DOI: 10.1039/c9ra07630a

rsc.li/rsc-advances

\section{Green synthesis of zinc oxide nanostructures and investigation of their photocatalytic and bactericidal applications $\uparrow$}

\author{
Mebrahtu Hagos Kahsay, (DD *a Aschalew Tadesse, ${ }^{\text {b }}$ Dharamasoth RamaDevi, ${ }^{\mathrm{c}}$ \\ Neway Belachew (DD) ${ }^{d}$ and K. Basavaiah ${ }^{\mathrm{e}}$
}

We report a facile one-pot green synthesis of zinc oxide $(\mathrm{ZnO})$ nanostructures using aqueous leaf extract of Dolichos Lablab L. as the reducing and capping agent. The optical properties, structure and morphology of the as-synthesized ZnO nanostructures have been characterized by UV-Visible spectroscopy (UV-Vis), Fourier transform infrared spectroscopy (FT-IR), X-ray diffraction (XRD), field emission scanning electron microscopy (FE-SEM) supported with energy dispersive X-ray spectroscopy (EDX), and transmission electron microscopy (TEM). TEM analysis revealed that the as-synthesized $\mathrm{ZnO}$ nanostructures have an average particle diameter of $29 \mathrm{~nm}$. XRD patterns confirmed the formation of phase-pure ZnO nanostructures with a hexagonal wurtzite structure. The synthesized $\mathrm{ZnO}$ nanostructures were used as a catalyst in the photodegradation of methylene blue (MB), rhodamine B (RhB) and orange II (OII) under visible and near-UV irradiation. The results showed the highest efficiency of photodegradation of $\mathrm{ZnO}$ nanostructures for $\mathrm{MB}(80 \%), \mathrm{RhB}(95 \%)$ and $\mathrm{Oll}(66 \%)$ at $\mathrm{pH}$ values of 11,9 and 5, respectively, in a 210 min time interval. In addition, the antimicrobial activity of the $\mathrm{ZnO}$ nanostructures using the agar well diffusion method against Bacillus pumilus and Sphingomonas paucimobilis showed the highest zones of inhibition of $18 \mathrm{~mm}$ and $20 \mathrm{~mm}$, respectively. Hence, $\mathrm{ZnO}$ nanostructures have the potential to be used as a photocatalyst and bactericidal component.

\section{Introduction}

The textile, paper, cosmetic, rubber, food and leather industries dispose of a lot of solid waste and discharge wastewater contaminated with dyes directly or indirectly into rivers, lakes and oceans. ${ }^{1}$ Studies have shown that the dye industry discharges about 100 tons of dyes per year into the environment, such as rivers and water springs. ${ }^{2,3}$ Dye pollution in water bodies can become incorporated into the food chain, leading to the destruction of aquatic ecosystems and potentially resulting in various negative health effects, such as carcinogenic, teratogenic and mutagenic effects. ${ }^{4,5}$ A xanthene class dye, rhodamine $\mathrm{B}$ is a cationic dye that is highly soluble in water and is

${ }^{a}$ Department of Chemistry, Woldia University, P.O.BOX 400, Woldia, Ethiopia. E-mail: hagosmebrahtu@gmail.com

${ }^{b}$ Department of Applied Chemistry, Adama Science and Technology University, Adama, P.O.BOX 1888, Ethiopia

${ }^{c} A U$ College of Pharmaceutical Sciences, Andhra University, Visakhapatnam, 530003, India

${ }^{d}$ Department of Chemistry, Debre Berhan University, Debre Berhan, P.O.BOX 445, Ethiopia

${ }^{e}$ Department of Inorganic \& Analytical Chemistry, Andhra University, Visakhapatnam, 530003, India

$\uparrow$ Electronic supplementary information (ESI) available. See DOI: 10.1039/c9ra07630a often used as a colorant in textiles and foodstuffs. In addition, it is a well-known fluorescent water tracer. ${ }^{6}$ If it is consumed by any means by humans or animals, it can cause irritation to the skin, eyes and respiratory tract. ${ }^{7}$ Crystal violet is also a cationic dye that has mutagenic and mitotic properties. Dyes such as crystal violet and methylene blue are used in huge quantities in textile and paper dyeing, and worldwide, about 15\% of such dyes are released into the environment after use as wastewater. These dye compounds dissolve in water bodies in the concentration range of 10 to $200 \mathrm{mg} \mathrm{l}^{-1}$, resulting in serious water pollution globally. ${ }^{8}$ Due to the increasing pollution of water resources, today more than 1.1 billion people lack access to safe drinking water, especially in developing countries. Therefore, it has been a great ambition of researchers to develop new processes and technologies capable of selectively separating and removing target inorganic and organic pollutants from wastewater. Advances in science and technology have resulted in various approaches, such as coagulation, filtration with coagulation, precipitation, ozonation, adsorption, ion exchange, reverse osmosis and advanced oxidation processes, to remove organic pollutants. ${ }^{9}$ Very recently, nano-enabled technologies have shown promising potential in the field of water purification and wastewater treatment. ${ }^{10}$

$\mathrm{ZnO}$ nanoparticles (NPs) have a range of applications in new light-emitting devices, solar cells, biosensors, and 
photocatalysts. ${ }^{\mathbf{1 1 , 1 2}}$ Moreover, ZnO NPs are considered to be an effective futuristic water purification material. ZnO NPs also show an extraordinary antibacterial property due to their expanded specific surface area, as the reduced particle size leads to enhanced particle surface reactivity. The bio-safe material, $\mathrm{ZnO}$, can exhibit photo-oxidizing and photocatalysis impacts on chemical and biological species. ${ }^{12}$ In comparison to ZnO NPs synthesized by chemical means, green-synthesized ZnO NPs show vigorous antibacterial effects at a very low concentration. ${ }^{\mathbf{1 3 , 1 4}} \mathrm{ZnO}$ NPs have diverse applications in fields such as anticancer, antidiabetic, antibacterial and antifungal treatments, drug delivery, and agricultural technologies. ${ }^{15-19}$ Their nanosized nature leads to changes in the chemical, mechanical, electrical, structural, morphological and optical properties of the material, which enables NPs to interact in a unique manner with cell biomolecules, facilitating the physical exchange of NPs into inner cellular structures. ${ }^{20}$

Even though the synthesis of ZnO NPs via green synthesis routes using biological systems such as bacteria, fungi, yeast, and plants ${ }^{21,22}$ has been reported, it has been mentioned that handling and controlling plant material is easier when compared to the other biological systems. ZnO NPs have been prepared via plant-mediated synthesis using various plant species. ${ }^{23-33}$ Extracts of these plants have been employed as reducing and stabilizing agents during the green synthesis of various sized ZnO nanostructures. To the best of our knowledge, Dolichos lablab Linn has never been reported for the synthesis of ZnO nanostructures. Thus, we decided to use this plant species due to its wide availability, low cost, edible nature, low toxicity and solubility in water as an eco-friendly solvent. Dolichos lablab L. belongs to the family Leguminosae (Fabaceae). The genus Lablab is native to India ${ }^{34}$ and is widespread in every corner of the world. Dolichos lablab L. is rich in minerals, vitamins, proteins, essential amino acids, dietary fiber, starch, flavonoids, steroids, glycosides, trypsin inhibitors, hydrogen cyanide, oxalate, haemagglutinin units, phytate, tannin, saponin, alkaloids and polyphenol. ${ }^{35,36}$

In this paper, ZnO nanostructures were synthesized using a facile green synthesis approach, with Dolichos lablab L. leaf extract used as a reducing and capping agent. The as-prepared ZnO nanostructures were characterized using different spectroscopy and microscopy instruments. The photocatalytic efficiency of the $\mathrm{ZnO}$ nanostructures was studied under combined visible and near-UV photoirradiation for three model organic dye pollutants, i.e., MB, RhB, and OII. Furthermore, the antimicrobial activity of the green-synthesized $\mathrm{ZnO}$ nanostructures was evaluated against pathogenic Gram-positive (Bacillus pumilus) and Gram-negative (Sphingomonas paucimobilis) microorganisms.

\section{Experimental}

\section{Materials}

All chemicals used in this study were analytical grade and were used without further purification. Zinc acetate dihydrate extra pure $\left(\mathrm{Zn}\left(\mathrm{CH}_{3} \mathrm{COO}\right)_{2} \cdot 2 \mathrm{H}_{2} \mathrm{O}\right)$ and purified sodium hydroxide pellets $(\mathrm{NaOH})$ were obtained from Merck, India. $\mathrm{MB}$, RhB and
OII were received from Sigma-Aldrich. The metal halide lamp (visible $\left(452.5 \mathrm{~W} \mathrm{~m}^{-2}\right)$ and $\mathrm{UV}\left(70.2 \mathrm{~W} \mathrm{~m}^{-2}\right)$ photoirradiation intensity) was from Fast track, India. The leaves of Dolichos lablab L. were collected from Andhra University, Visakhapatnam, India. The plant was authenticated by Dr S. B. Padal, voucher specimen number - AU (AUH) 22232, in Andhra University Herbarium, Botany Department, Andhra University, Andhra Pradesh, India. Sources of standard strains of Grampositive (Bacillus pumilus) and Gram-negative (Sphingomonas paucimobilis) bacteria were from Adhya Biosciences Pvt. Ltd., Visakhapatnam.

\section{Preparation of aqueous leaf extract of Dolichos lablab $\mathrm{L}$.}

Dolichos lablab L. leaves were collected and then washed with double distilled water to remove any dust. $20.0 \mathrm{~g}$ of leaves of Dolichos lablab L. (Fig. 1a) were weighed and heated in $100 \mathrm{ml}$ of Milli-Q water at $70{ }^{\circ} \mathrm{C}$ for $30 \mathrm{~min}$. The resultant extract was allowed to cool and then filtered with Whatman no. 42 filter paper to produce greenish yellow filtrate (Fig. 1b). Finally, the obtained aqueous extract was stored in a refrigerator at $4{ }^{\circ} \mathrm{C}$ for the synthesis of $\mathrm{ZnO}$ nanostructures.

\section{Synthesis of zinc oxide nanostructures using aqueous leaf extract of Dolichos lablab $\mathrm{L}$.}

In a typical synthesis, $10.0 \mathrm{ml}(1 \%)$ of aqueous leaf extract of Dolichos Lablab L., $0.5 \mathrm{~g}(2.73 \mathrm{mmol})$ zinc acetate dihydrate, and $10.0 \mathrm{mmol} \mathrm{NaOH}$ and $80.0 \mathrm{ml}$ of Milli-Q water were refluxed at $70{ }^{\circ} \mathrm{C}$ under magnetic stirring for $1 \mathrm{~h}$ until a pale white precipitate formed, which indicated the synthesis of $\mathrm{ZnO}$ nanostructures (Fig. 1c). The formed $\mathrm{ZnO}$ nanostructures were centrifuged and washed periodically with Milli-Q water and ethanol in order to remove unreacted precursors. Finally, $\mathrm{ZnO}$ precipitate was dried under vacuum at room temperature.

\section{Characterization of zinc oxide nanostructures}

Optical properties were analyzed using UV-Vis spectrophotometers (UV-2600 SHIMADZU) and (UV-500, Thermo Electron Corporation) in the wavelength range of $200-800 \mathrm{~nm}$. FT-IR spectra were recorded over the range of 4000-400 $\mathrm{cm}^{-1}$ using a SHIMADZU-IR PRESTIGE-2 spectrometer. Powder XRD patterns were recorded on a PANalytical X'pert Pro diffractometer at 0.02 degree per second scan rate using $\mathrm{CuK} \alpha_{1}$ radiation $(\lambda=1.5406 \AA)$. The morphology and elemental composition were characterized using FE-SEM (JEOL, JSM-7600F) at an accelerating voltage of 0.1 to $30 \mathrm{kV}$, equipped with EDX. The size and shape of the ZnO nanostructures were investigated by TEM (TEM model FEI TECNAI G2 S-Twin).

\section{Photocatalytic activity of ZnO nanostructures}

The photocatalytic degradation of three organic dye pollutants, i.e. $\mathrm{MB}, \mathrm{RhB}$ and $\mathrm{OII}$, using the synthesized $\mathrm{ZnO}$ nanostructures as a semiconductor catalyst system in a batch reactor under visible and near-UV photoirradiation, was investigated. Different initial concentrations of dye solution $(5,25,50$ and $100 \mathrm{ppm}$ ) were prepared from dye powder, with the $\mathrm{pH}$ value of 

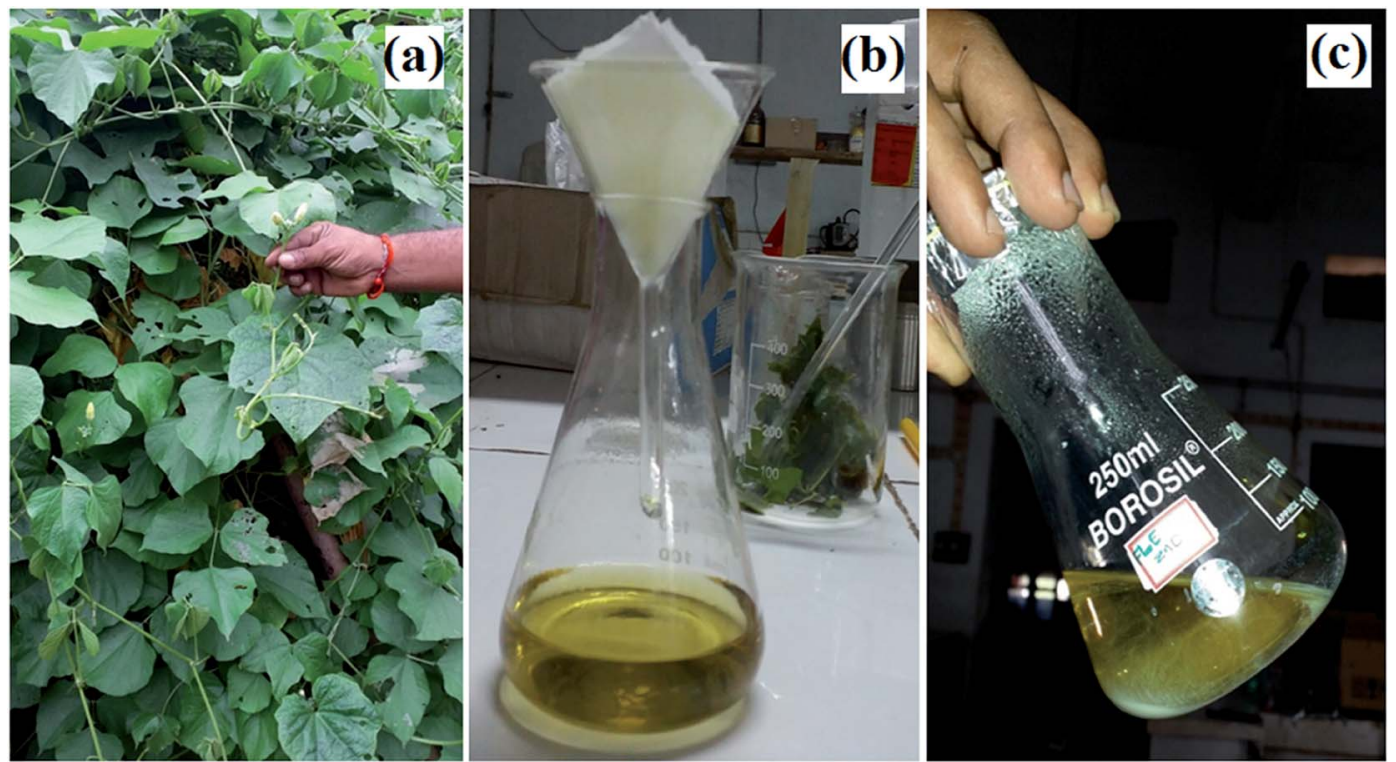

Fig. 1 Images of Dolichos lablab L.: (a) habitat, (b) leaf extract, and (c) ZnO nanostructures.

Table 1 Preliminary phytochemical investigation of aqueous leaf extract of Dolichos lablab L. ${ }^{a}$

\begin{tabular}{llll} 
S. no. & Test & Chemical constituents & Result \\
\hline 1 & Mayer's test & Alkaloid & + \\
2 & $\mathrm{FeCl}_{3}$ solution & Phenol & + \\
3 & $\mathrm{NaOH}$ & Flavonoid & + \\
4 & Fehling solution & Carbohydrate & - \\
5 & Conc. $\mathrm{HNO}_{3}$ & Amino acid and protein & + \\
6 & Methanol, chloroform, $\mathrm{H}_{2} \mathrm{SO}_{4}$ & Terpenoid & + \\
7 & Shake with water & Saponin & +
\end{tabular}

${ }^{a}$ Where, $(+)$ indicates presence and $(-)$ indicates absence.

the solution maintained at $\mathrm{pH}=5,9,11$, and poured into a $100 \mathrm{ml}$ beaker. $5 \mathrm{ppm}$ model organic dye, $1 \mathrm{~g} \mathrm{l}^{-1} \mathrm{ZnO}$ nanostructure powder and $10 \mu \mathrm{l} 30 \% \mathrm{H}_{2} \mathrm{O}_{2}$ (to increase the concentration of dissolved oxygen) were mixed to form a suspended dye solution, and the beaker was covered with aluminum foil to keep the system dark for the first $30 \mathrm{~min}$ under magnetic stirring. At the adsorption-desorption equilibrium, $3 \mathrm{ml}$ of the colloidal suspension was taken into a clean vial and labeled as $0 \mathrm{~min}$. The subsequent batches were irradiated with a metal halide lamp (visible and near-UV) while being magnetically stirred to ensure homogeneous mixing. Similarly, at every $30 \mathrm{~min}$ time interval, $3 \mathrm{ml}$ of the colloidal suspension was removed and placed into a vial, and labelled as $30,60,90,120,150,180$ and $210 \mathrm{~min}$. Finally, the absorption of each solution was measured in the wavelength range from 200 to $800 \mathrm{~nm}$ using UV-Vis spectroscopy and the percentage of dye degradation (\%) was calculated using eqn (1).

$$
\text { Dye degradation }(\%)=\left(C_{0}-C\right) / C_{0} \times 100
$$
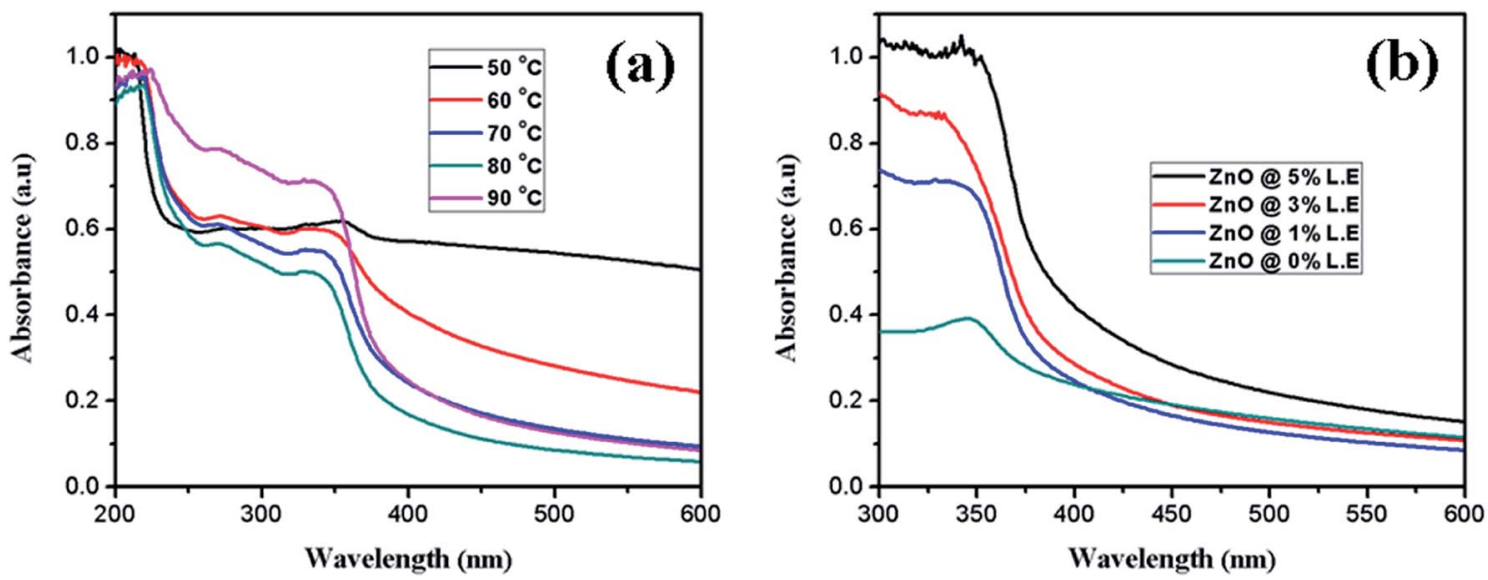

Fig. 2 UV-Vis absorption spectra of synthesized ZnO nanostructures at different (a) temperatures, (b) percentages of leaf extract. 

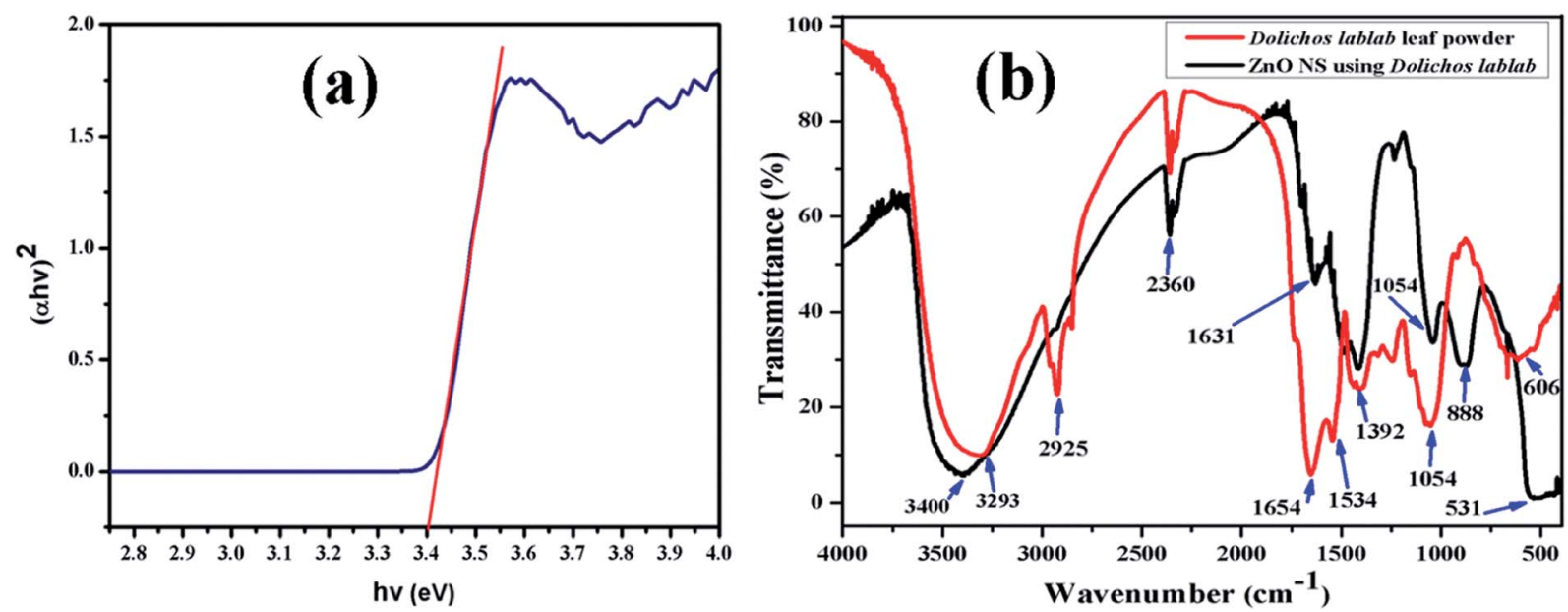

Fig. 3 (a) Tauc plot of ZnO nanostructures, (b) FT-IR spectra of aqueous leaf extract of Dolichos lablab L. and the as-synthesized ZnO nanostructures.

$C_{0}$ is the initial concentration of dye (ppm) before the addition of catalyst and photoirradiation and $C$ is the concentration of dye at equilibrium ( $\mathrm{ppm}$ ) after the addition of catalyst and exposure to photoirradiation.

\section{Antibacterial activity screening}

The antimicrobial activity was assessed by employing $24 \mathrm{~h}$ cultures with $\mathrm{ZnO}$ nanostructures by using the agar well diffusion method..$^{37}$ The medium was sterilized by autoclaving at $120^{\circ} \mathrm{C}\left(15 \mathrm{lb} \mathrm{in}^{-2}\right)$. About $20 \mathrm{ml}$ of nutrient agar medium/potato dextrose agar seeded with the respective strains of bacteria was transferred aseptically into each sterilized Petri plate. The plates were left at room temperature for solidification. In each plate, a single well of $6 \mathrm{~mm}$ diameter was made using a sterile borer. The ZnO nanostructures were freshly reconstituted with suitable solvent (DMSO) and tested at various concentrations (2.5, 5 , and $10 \mathrm{mg} \mathrm{ml}^{-1}$ ). The samples, control, and standard (Ciprofloxacin) were placed in $6 \mathrm{~mm}$ diameter wells. $5 \mu \mathrm{g} \mathrm{ml}$ standard was used as a positive control. Assays were incubated at $37 \pm 2{ }^{\circ} \mathrm{C}$. The activity diameter of the zone of inhibition was measured using the Himedia antibiotic zone scale.

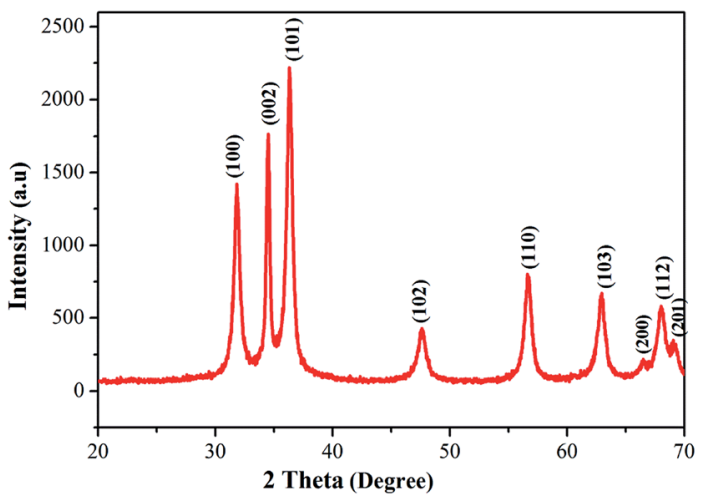

Fig. 4 Powder XRD pattern of $\mathrm{ZnO}$ nanostructures synthesized using aqueous leaf extract of Dolichos lablab L.

\section{Results and discussion}

The green synthesis of $\mathrm{ZnO}$ nanostructures using leaf extract of Dolichos lablab L. provides a simple, low cost and environmentally friendly route without the use of toxic organic solvents and hazardous materials. Moreover, in this procedure, there is no need to use high temperature, pressure or energy. Aqueous leaf extract of Dolichos lablab L. performed as a reducing and capping agent during $\mathrm{ZnO}$ nanostructure synthesis without releasing toxic chemicals to the environment. The preliminary phytochemical analysis of the present plant extract is presented in Table 1. The results demonstrated that alkaloid, phenol, flavonoid, amino acid, protein, terpenoid and saponin were the qualitatively identified constituents of Dolichos lablab L. in this study, in agreement with previous reports. ${ }^{38,39}$

\section{UV-Vis analysis}

The absorption spectrum of synthesized $\mathrm{ZnO}$ nanostructures using aqueous leaf extract of Dolichos Lablab L. is presented in Fig. 2. Synthesis of $\mathrm{ZnO}$ nanostructures was optimized by increasing the temperature of the reaction from $60{ }^{\circ} \mathrm{C}$ to $90{ }^{\circ} \mathrm{C}$ (Fig. 2a) and volume of the plant extract from $0 \%$ to $5 \%$

Table 2 Structure and geometric parameters of $\mathrm{ZnO}$ nanostructures

\begin{tabular}{lllll}
\hline $2 \theta$ (degree) & FWHM $(\beta)$ & $d$-spacing $(\AA)$ & $\cos \theta$ & Crystallite size $(\mathrm{nm})$ \\
\hline 8.3932 & 1.3056 & 10.52625 & 0.99732 & 6.38 \\
31.8365 & 0.4080 & 2.80859 & 0.96165 & 21.16 \\
34.5150 & 0.2448 & 2.59651 & 0.95498 & 35.51 \\
36.3340 & 0.1224 & 2.47059 & 0.95015 & 71.38 \\
47.6293 & 0.5712 & 1.90772 & 0.91486 & 15.88 \\
56.6423 & 0.0816 & 1.62369 & 0.88030 & 115.55 \\
62.9124 & 0.2448 & 1.47610 & 0.85304 & 39.75 \\
66.5366 & 0.5712 & 1.40422 & 0.83611 & 17.38 \\
68.0506 & 0.4488 & 1.37662 & 0.82879 & 22.31 \\
69.1192 & 0.6528 & 1.35792 & 0.82354 & 15.44 \\
Average & & & & 36.07
\end{tabular}


(Fig. 2b). The characteristic absorption peak was observed from 330 to $354 \mathrm{~nm}$ at different temperatures. The results indicate that the intensity of the absorption peak of the synthesized $\mathrm{ZnO}$ nanostructures increased with increasing temperature of the reaction and percentage of plant extract. When the reaction mixture was optimized to $90{ }^{\circ} \mathrm{C}$, a characteristic peak was observed at $329 \mathrm{~nm}$. Mang et al. ${ }^{40}$ reported a similar result. However, ZnO nanostructures synthesized using 5\% plant extract showed a characteristic peak at $342 \mathrm{~nm}$. In addition, increasing the temperature of the reaction mixture and concentration of plant extract showed a blue shift, i.e., a decrease in the size of the $\mathrm{ZnO}$ nanostructures.

\section{UV-DRS and FT-IR analysis}

The $\mathrm{ZnO}$ nanostructure surface absorbed radiation in the UV region at $\lambda=366 \mathrm{~nm}$, and its band gap was extrapolated to be $3.4 \mathrm{eV}$ from the Tauc relation (eqn. (2)). In the literature, the band gap of ZnO NPs synthesized using Abutilon indicum plant extract is reported to be $3.37 \mathrm{eV}$ at a wavelength of $368 \mathrm{~nm} .^{\mathbf{4 0 , 4 1}}$ Fig. 3a represents the Tauc plot of the as-synthesized $\mathrm{ZnO}$ nanostructures. The photocatalytic efficiency of the $\mathrm{ZnO}$ nanostructures under visible and near-UV photoirradiation is limited due to its wide band gap. In fact, the band gap of $\mathrm{ZnO}$ confines its photocatalytic activity within the UV light range. As a result, it can utilize only $4 \%$ of the incident solar radiation. ${ }^{42}$ Therefore, a very small amount, i.e., $10 \mu \mathrm{l} 30 \% \mathrm{H}_{2} \mathrm{O}_{2}$, was added to the dye solution to increase the concentration of dissolved oxygen during degradation.

$$
\alpha h \nu=A^{\prime}\left(h \nu-E_{\mathrm{g}}\right)^{n}
$$

Here, $\alpha$ is the absorption coefficient $(\alpha=2.303 A / t), A$ is absorbance, $t$ is the path length of the wave equal to the thickness of the cuvette, $A$ is a proportionality constant, $h \nu$ is the photon energy and $E_{\mathrm{g}}$ is the energy band gap for the allowed direct transition of value $n$ equal to $1 / 2$.

FT-IR analysis was done to identify the possible functional groups involved in the reduction of zinc ions and the capping of reduced ZnO nanostructures. The FT-IR spectrum of the leaf extract of Dolichos lablab L. is shown in Fig. 3b, which shows absorption bands at 3293, 2925, 2360, 1654, 1534, 1392, 1054 and $606 \mathrm{~cm}^{-1}$, due to hydrogen bonded $\mathrm{O}-\mathrm{H}$ stretching of alcohol or phenol functional groups, $\mathrm{sp}^{3} \mathrm{C}-\mathrm{H}$ stretching of alkane groups, $\mathrm{CO}_{2}$ interference, $\mathrm{C}=\mathrm{O}$ stretching of amide groups, $\mathrm{N}-\mathrm{O}$ asymmetric stretching, $\mathrm{N}-\mathrm{O}$ symmetric stretching, $\mathrm{C}-\mathrm{O}$ stretching of carboxylic and ester groups and $\mathrm{C}-\mathrm{C}$ bending. ${ }^{43}$ The FT-IR spectrum of Dolichos lablab L. mediated $\mathrm{ZnO}$ nanostructures shows absorption bands at 3400, 2360, 1631, 1392, 1044, 888 and $531 \mathrm{~cm}^{-1}$, due to hydrogen bonded $\mathrm{O}-\mathrm{H}$ stretching of alcohol or phenolic groups, $\mathrm{CO}_{2}$ interference, $\mathrm{C}=\mathrm{O}$ stretching of amide, $\mathrm{N}-\mathrm{O}$ symmetric stretching, $\mathrm{C}-\mathrm{O}$ stretching of carboxylic acid, $\mathrm{CH}_{3}$ wag and $\mathrm{Zn}-\mathrm{O}$ bending vibrations. Hence, phytoconstituents of Dolichos lablab L. leaf
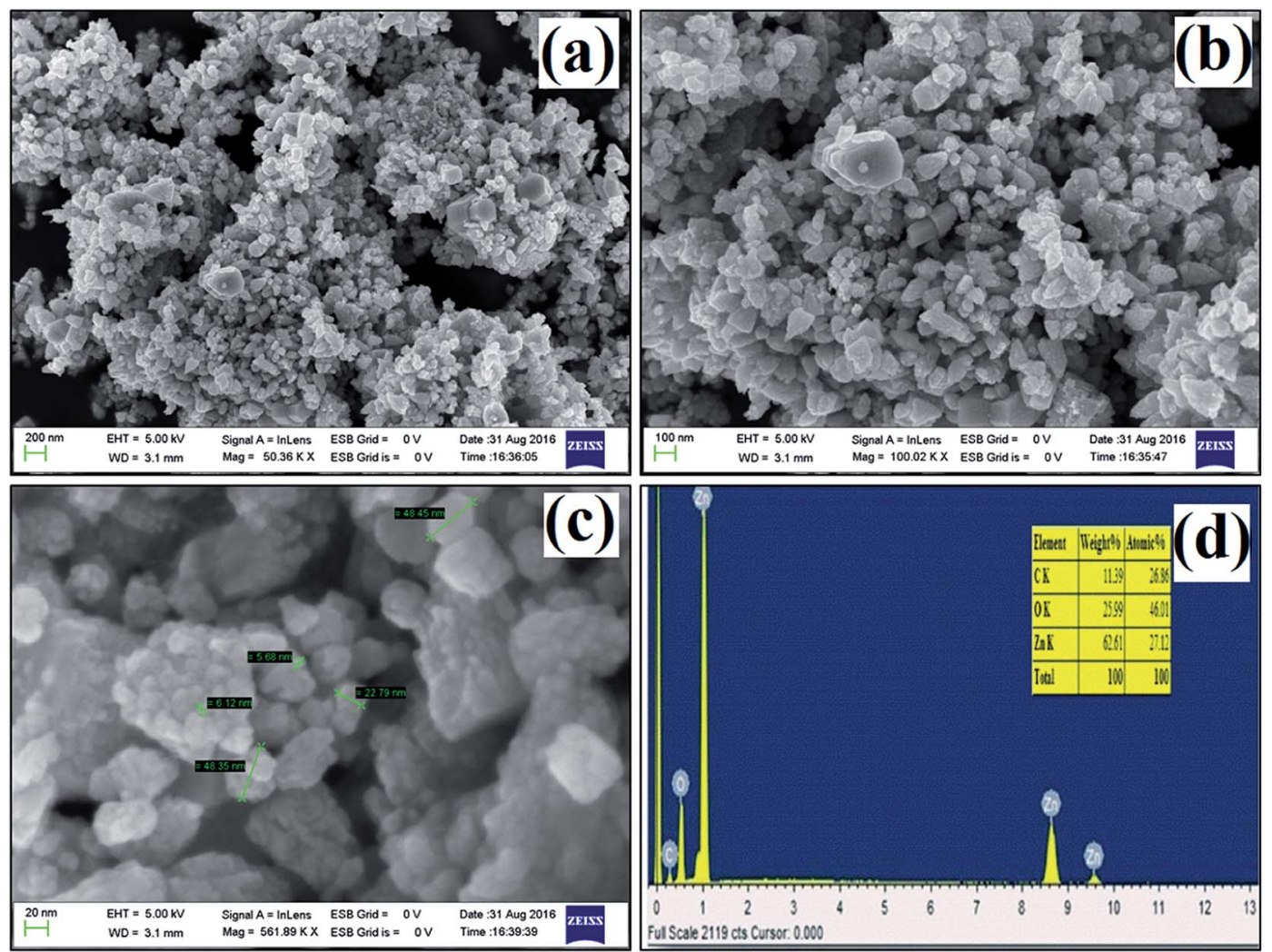

Fig. 5 (a-c) FE-SEM images at different magnifications, (d) EDX spectrum of ZnO nanostructures synthesized using aqueous leaf extract of Dolichos lablab L. 
extract were used as capping and reducing agents. Similarly, Udayabhanu et al. ${ }^{44}$ reported the $\mathrm{Zn}-\mathrm{O}$ bending vibration of $\mathrm{ZnO}$ super-structures synthesized using skin extract of Vitis labrusca to be $532 \mathrm{~cm}^{-1}$.

\section{XRD analysis}

The phase purity and crystallinity of the as-prepared $\mathrm{ZnO}$ nanostructures was investigated using X-ray diffraction. The XRD patterns of the obtained $\mathrm{ZnO}$ nanostructures are shown in Fig. 4. The XRD patterns of the $\mathrm{ZnO}$ nanostructures show $2 \theta$ values at $31.84^{\circ}, 34.52^{\circ}, 36.33^{\circ}, 47.63^{\circ}, 56.64^{\circ}, 62.91^{\circ}, 66.54^{\circ}$, $68.05^{\circ}$ and $69.12^{\circ}$, which correspond to (100), (002), (101), (102), (110), (103), (200), (112) and (201) planes of hexagonal wurtzite structure (JCPDS card no.: 36-1451). ${ }^{45}$ The broadening of the diffraction peaks clearly indicates the presence of nanoparticles in the product. In this study, an unusual larger intensity peak, which is deviant when compared to the standard and other studies, is observed at $2 \theta=34.52^{\circ}(002)$. The average crystallite size $(D)$ of the synthesized $\mathrm{ZnO}$ nanostructures was calculated using the Debye-Scherrer formula (eqn. (3)) to be $36 \mathrm{~nm}^{.6}$

$$
D=0.9 \lambda / \beta \cos \theta
$$

$D$ is the crystallite size (nm), $\lambda$ is the wavelength of $\mathrm{CuK} \alpha$ radiation (0.15406 $\AA$ ), $\beta$ is the full width at half maximum of the diffraction peak (in radian). Table 2 illustrates the structure and geometric parameters of the $\mathrm{ZnO}$ nanostructures.

\section{FE-SEM and EDX analysis}

The size and morphology of the synthesized ZnO nanostructures were studied using FE-SEM. Fig. 5a-c show FE-SEM images of the synthesized $\mathrm{ZnO}$ nanostructures under different magnifications, and their diameter range is 7 to $49 \mathrm{~nm}$. Hexagonal and triangular $\mathrm{ZnO}$ nanostructures are observed in Fig. 5a and b. The elemental composition of the synthesized ZnO nanostructures was confirmed by EDX, as shown in Fig. 5d. The elemental composition of $\mathrm{Zn}, \mathrm{O}$ and $\mathrm{C}$ in the $\mathrm{ZnO}$ nanostructures was found to be $27.1 \%, 46.0 \%$ and $26.9 \%$ by atomic mass, respectively. The presence of $\mathrm{C}$ in the peak indicates that organic molecules from the plant extract were used as capping agents during the formation of the $\mathrm{ZnO}$ nanostructures.

\section{TEM analysis}

The TEM images in Fig. 6 show irregularly shaped ZnO nanostructures. The diffraction rings in the SAED pattern match the XRD crystal planes, i.e., (100), (002), (101), (102), (110), (103), (200), (112) and (201). The average particle size of the assynthesized $\mathrm{ZnO}$ nanostructures was found to be $29 \mathrm{~nm}$. The
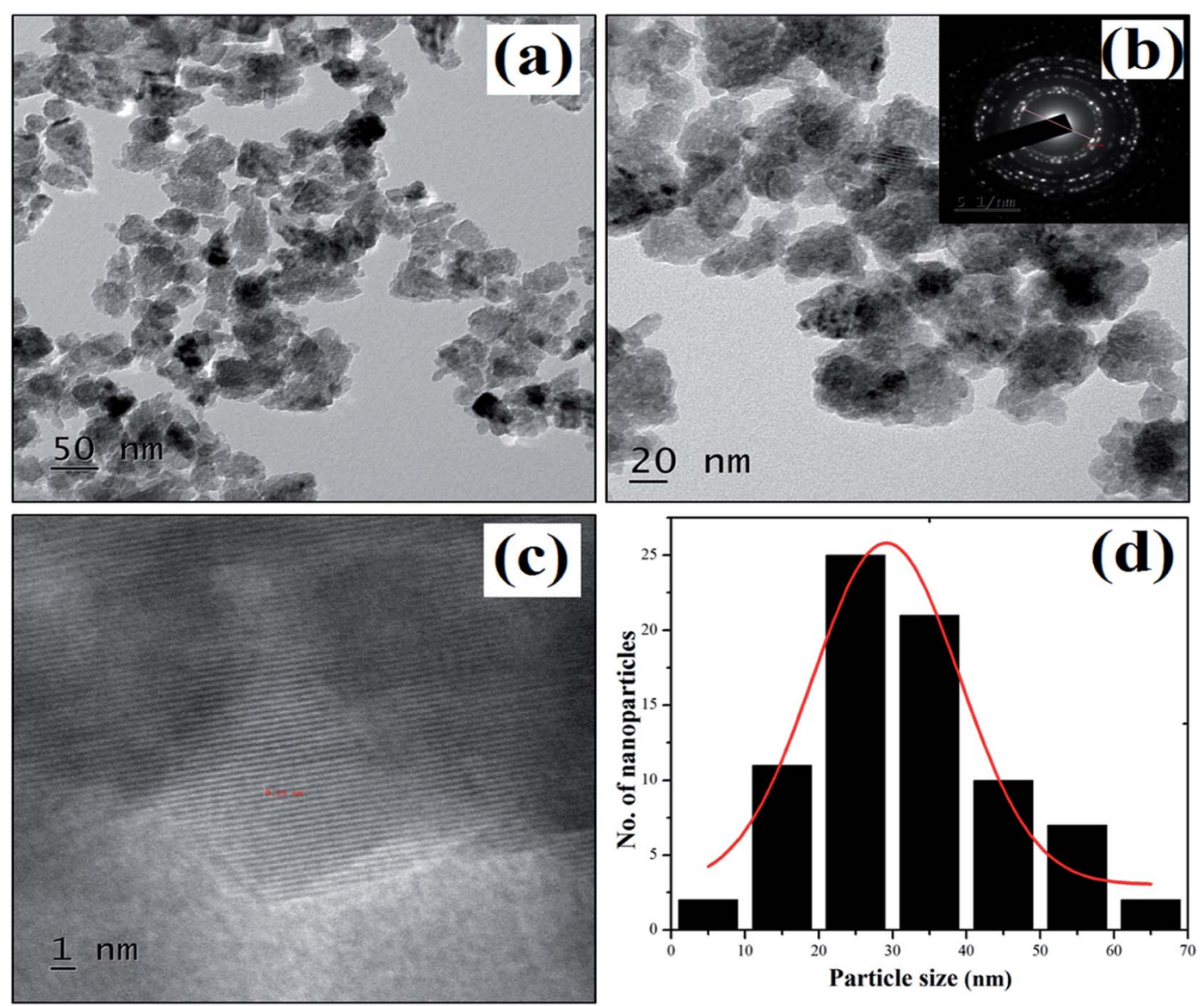

Fig. 6 (a-c) TEM images of plant mediated $\mathrm{ZnO}$ nanostructures and selected area electron diffraction patterns. (d) Particle size distribution histogram. 


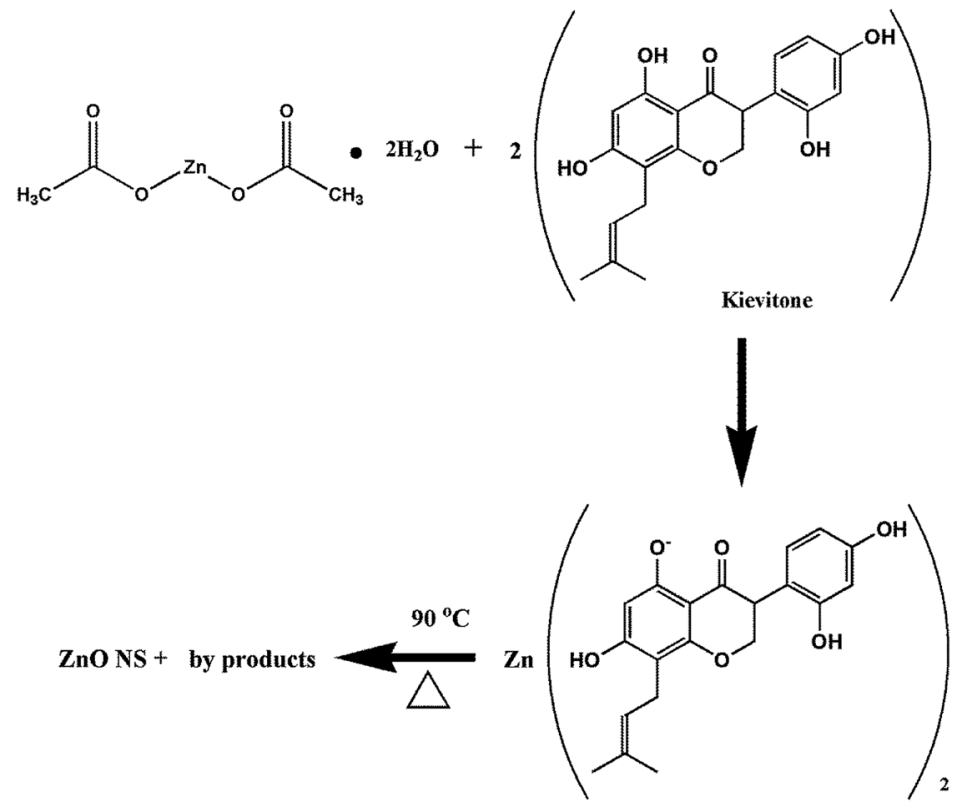

Fig. 7 Possible mechanism of synthesis of $\mathrm{ZnO}$ nanostructures using bioactive molecules.

less intense layering at the surface of the nanoparticles in Fig. 6 proves that the plant extract was also used as a capping agent. ${ }^{47}$

The formation of $\mathrm{ZnO}$ nanoparticles using zinc acetate in basic medium can be explained via different reactions such as dissolution, hydrolysis and precipitation. ${ }^{48}$ The proposed mechanism for the synthesis of the $\mathrm{ZnO}$ nanostructures using zinc acetate dihydrate and one of the biologically active phytoconstituents of Dolichos lablab L. as a reducing and capping agent is schematically illustrated in Fig. $7{ }^{49}$
Kinetic studies of dye degradation using $\mathrm{ZnO}$ nanostructures as photocatalyst

In this study, the as-synthesized $\mathrm{ZnO}$ nanostructures were used as a catalyst to degrade three organic dye pollutants, i.e., $\mathrm{MB}, \mathrm{RhB}$ and OII, under visible and near-UV photoirradiation. The maximum absorption of the dye was observed at $664 \mathrm{~nm}, 555 \mathrm{~nm}$ and $487 \mathrm{~nm}$, respectively. Fig. 8 shows the chemical structures of the three organic dyes. $50 \mathrm{ml}(5 \mathrm{ppm})$ organic dye was photodegraded using $1 \mathrm{~g} \mathrm{l}^{-1}$ of

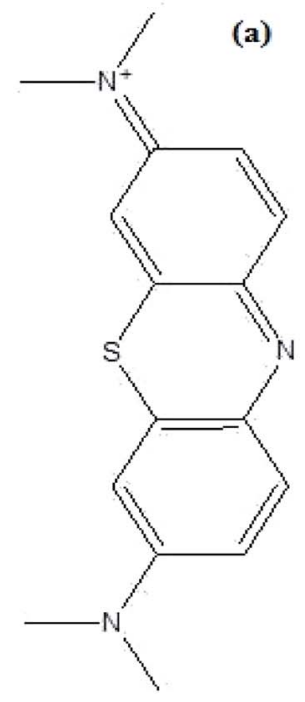

Methylene blue

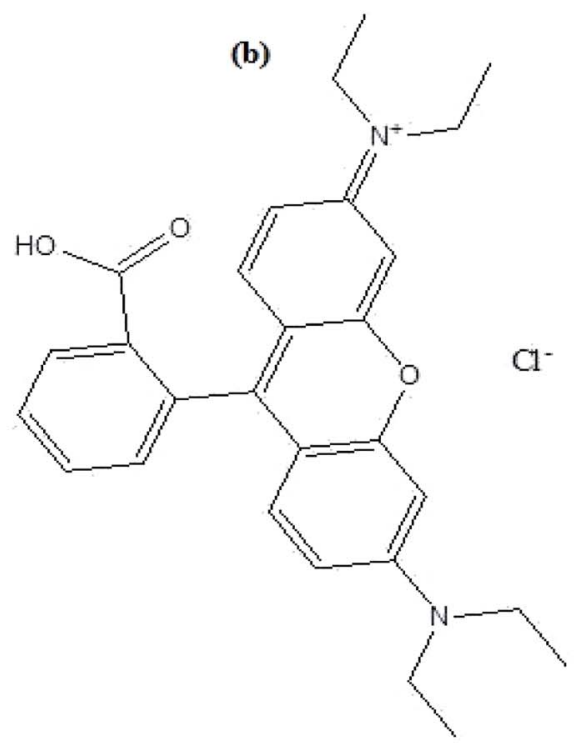

Rhodamine B<smiles>[NH2+]OS(=O)(=O)c1ccc(N/N=C2/C(=O)C=Cc3ccccc32)cc1</smiles>

Orange II

Fig. 8 Structures of (a) Methylene blue, (b) rhodamine B and (c) Orange II dyes. 
ZnO nanostructures under visible and near-UV photoirradiation, and the photocatalytic degradation efficiency of the $\mathrm{ZnO}$ nanostructures was studied at different initial dye concentrations, time intervals and pH values. Fig. 9-11 show time-dependent UV-Vis spectra of organic dyes and firstorder kinetic modeling under different $\mathrm{pH}$ conditions. The speed of the photocatalytic reaction or decolorization of dye for all three dyes increases with time span. The percentage of dye degradation was calculated using eqn (1).
A kinetic study of the catalytic degradation of the organic dyes using the $\mathrm{ZnO}$ nanostructures was performed using the Langmuir-Hinshelwood-Hougen-Watson (LH-HW) kinetic model (eqn. (4)). ${ }^{\mathbf{5 0 , 5 1}}$ For a hypothetical reaction, A (dye) $\rightarrow$ products. The algebraic form of the rate law, $r_{\mathrm{A}}$ may be a linear function of the concentration, as $-r_{\mathrm{A}}=k C_{\mathrm{A}}$, or it may be some other algebraic function of the concentration, as $-r_{\mathrm{A}}=k C_{\mathrm{A}}{ }^{2}$. However, for the photocatalytic degradation of organic dye that considers the adsorption properties of the reactant on the
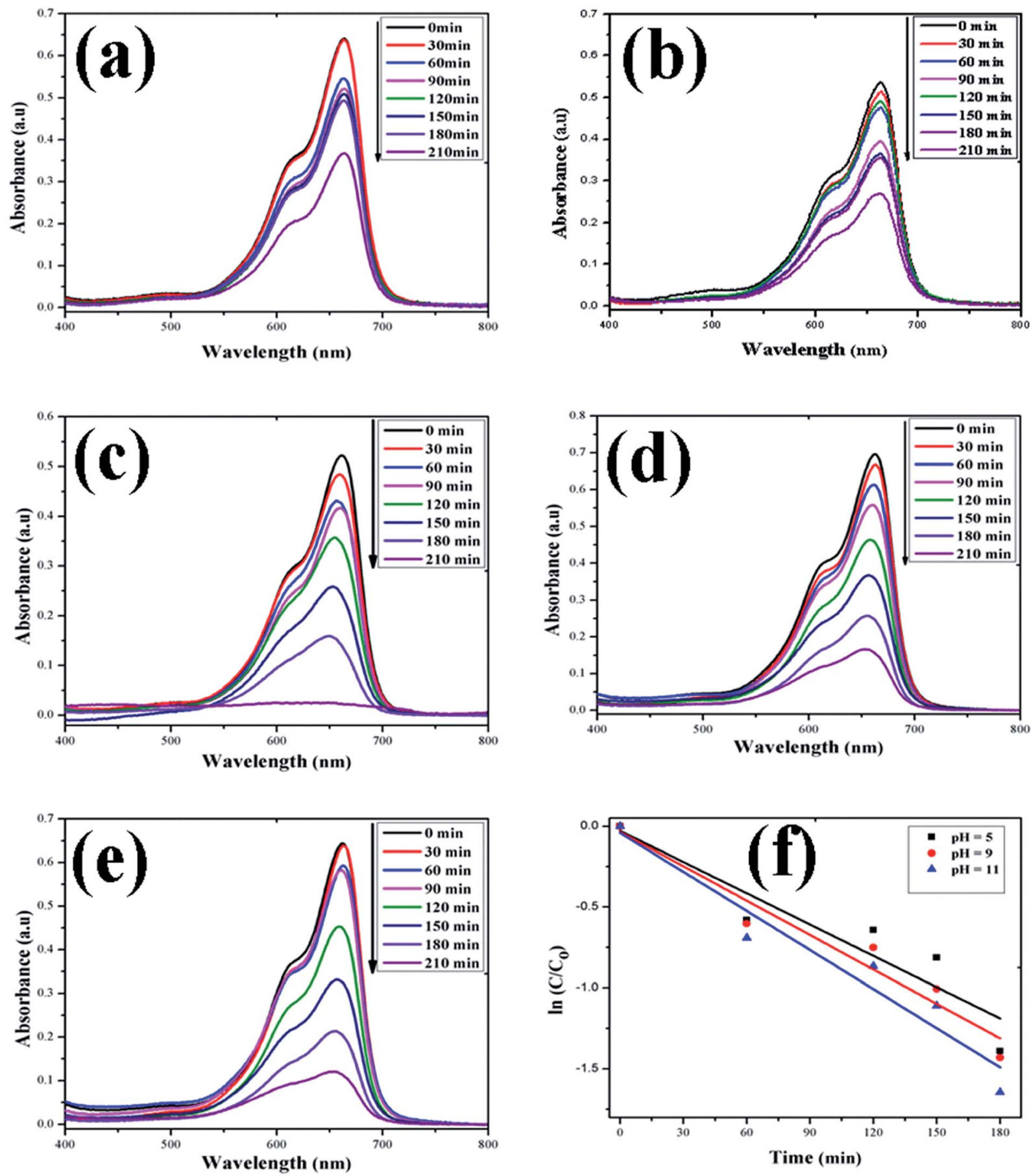

Fig. 9 Time-dependent UV-Vis spectra of (a) $\mathrm{MB}$ dye without $\mathrm{ZnO}$; (b) $\mathrm{MB}$ dye $+\mathrm{H}_{2} \mathrm{O}_{2}$; (c) $\mathrm{MB}$ dye $+\mathrm{ZnO}+\mathrm{H}_{2} \mathrm{O}_{2}$ at pH=5; (d) $\mathrm{MB}$ dye $+\mathrm{ZnO}+$ $\mathrm{H}_{2} \mathrm{O}_{2}$ at $\mathrm{pH}=$ 9; (e) $\mathrm{MB}$ dye $+\mathrm{ZnO}+\mathrm{H}_{2} \mathrm{O}_{2}$ at $\mathrm{pH}=11$. (f) First-order kinetic model of $\mathrm{MB}$ at different $\mathrm{pH}$ values. 
photocatalyst surface (e.g. $\mathrm{ZnO}$ ), the LH-HW rate law is expressed as:

$$
-r_{\mathrm{A}}=k C_{\mathrm{A}} /\left(1+k C_{\mathrm{A}}\right)
$$

Here, $-r_{\mathrm{A}}$ is the rate of disappearance of organic dye $\left(\mathrm{mol} \mathrm{s}^{-1}\right.$ $\left.\mathrm{dm}^{-3}\right), C_{\mathrm{A}}$ is organic dye concentration $\left(\mathrm{mol} \mathrm{dm}{ }^{-3}\right)$, and $k$ is the rate constant.
After rearrangement and integrating both sides of eqn (4), a plot of $\ln \left(C / C_{0}\right)$ vs. $t$ under different $\mathrm{pH}$ conditions was fitted to the LH-HW kinetic model, as shown in Fig. 9f, $10 \mathrm{f}$ and 11f. The reaction rate constants $(k)$ for photocatalytic degradation of $\mathrm{MB}, \mathrm{RhB}$ and OII dyes were $9.14 \times$ $10^{-3} \min ^{-1}, 1.65 \times 10^{-2} \min ^{-1}$ and $5.10 \times 10^{-3} \mathrm{~min}^{-1}$, respectively. Similarly, their corresponding $R^{2}$ values were
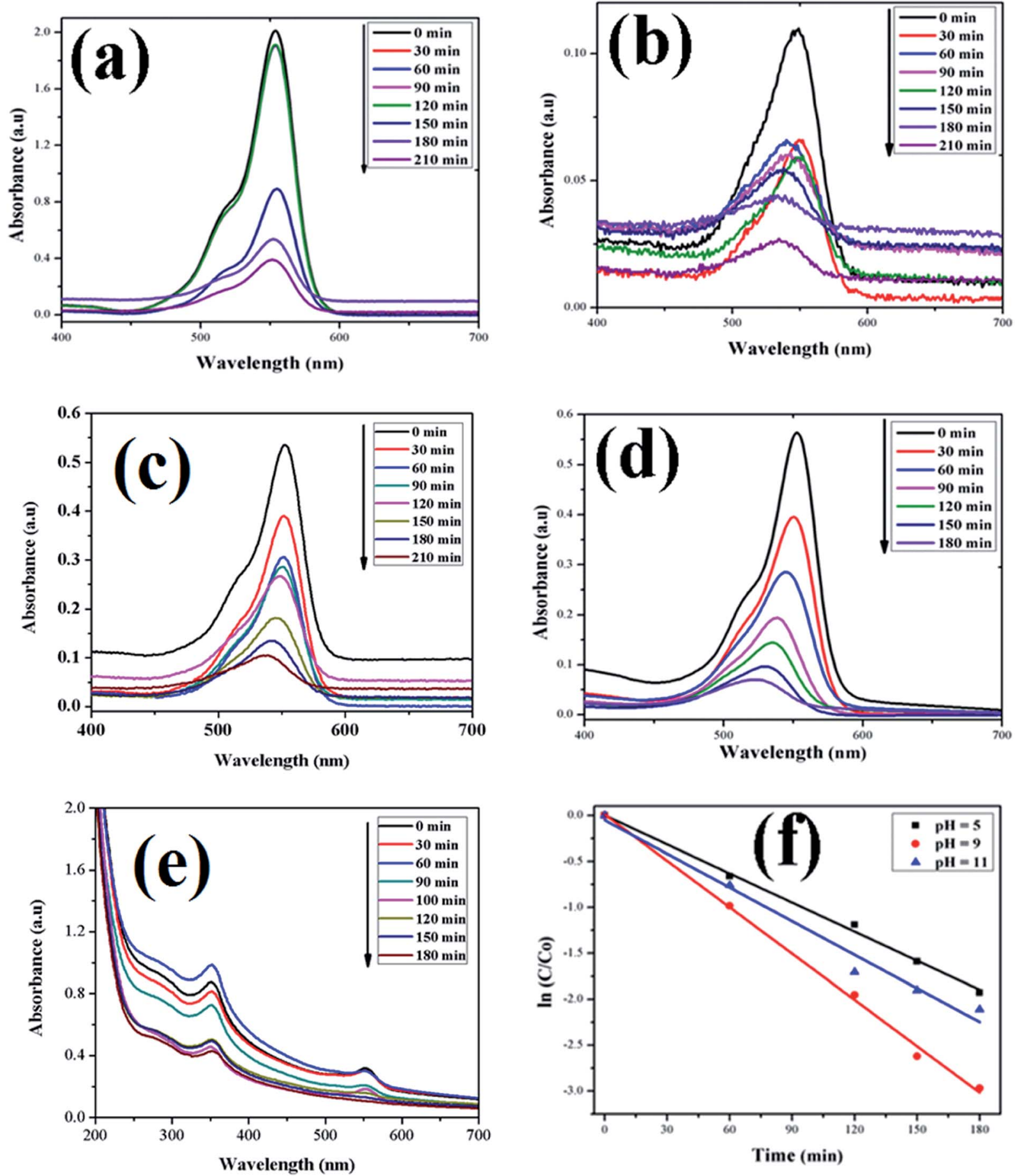

Fig. 10 Time-dependent UV-Vis spectra of (a) RhB dye without $\mathrm{ZnO}$; (b) $\mathrm{RhB}$ dye $+\mathrm{H}_{2} \mathrm{O}_{2}$; (c) $\mathrm{RhB}$ dye $+\mathrm{ZnO}+\mathrm{H}_{2} \mathrm{O}_{2}$ at pH $=5$; (d) $\mathrm{RhB}$ dye + $\mathrm{ZnO}+\mathrm{H}_{2} \mathrm{O}_{2}$ at $\mathrm{pH}=$ 9; (e) $\mathrm{RhB}$ dye $+\mathrm{ZnO}+\mathrm{H}_{2} \mathrm{O}_{2}$ at $\mathrm{pH}=$ 11. (f) First-order kinetic model of RhB at different $\mathrm{pH}$ values. 
$0.829,0.996$ and 0.994 , respectively. It can be concluded that the photocatalytic degradation of $\mathrm{MB}, \mathrm{RhB}$ and OII dyes using the $\mathrm{ZnO}$ nanostructure photocatalyst follows a pseudofirst-order kinetic model in this study. However, Rana et al. ${ }^{\mathbf{2}}$ reported that the photocatalytic degradation of $\mathrm{RhB}(5 \mathrm{ppm})$ using ZnO NPs synthesized from Terminalia chebula fruit extract had a rate constant of $0.228 \mathrm{~h}^{-1}$ and degradation efficiency of $70 \%$ after $5 \mathrm{~h}$.
The adsorption of organic dyes on the surface of $\mathrm{ZnO}$ nanostructures was influenced by the $\mathrm{pH}$ of the dye solution. Varying the $\mathrm{pH}$ of the dye solution changed the value of the percentage of dye degradation for MB, RhB and OII, as shown in Fig. 12a-c. Similarly, the catalyst dose of the ZnO nanostructures also influenced the photocatalytic degradation of $\mathrm{MB}$ (Fig. 12d). The photocatalytic degradation of dyes increased with increasing photocatalyst dose per adsorbent $\left(0.5 \mathrm{~g} \mathrm{l}^{-1}\right.$,
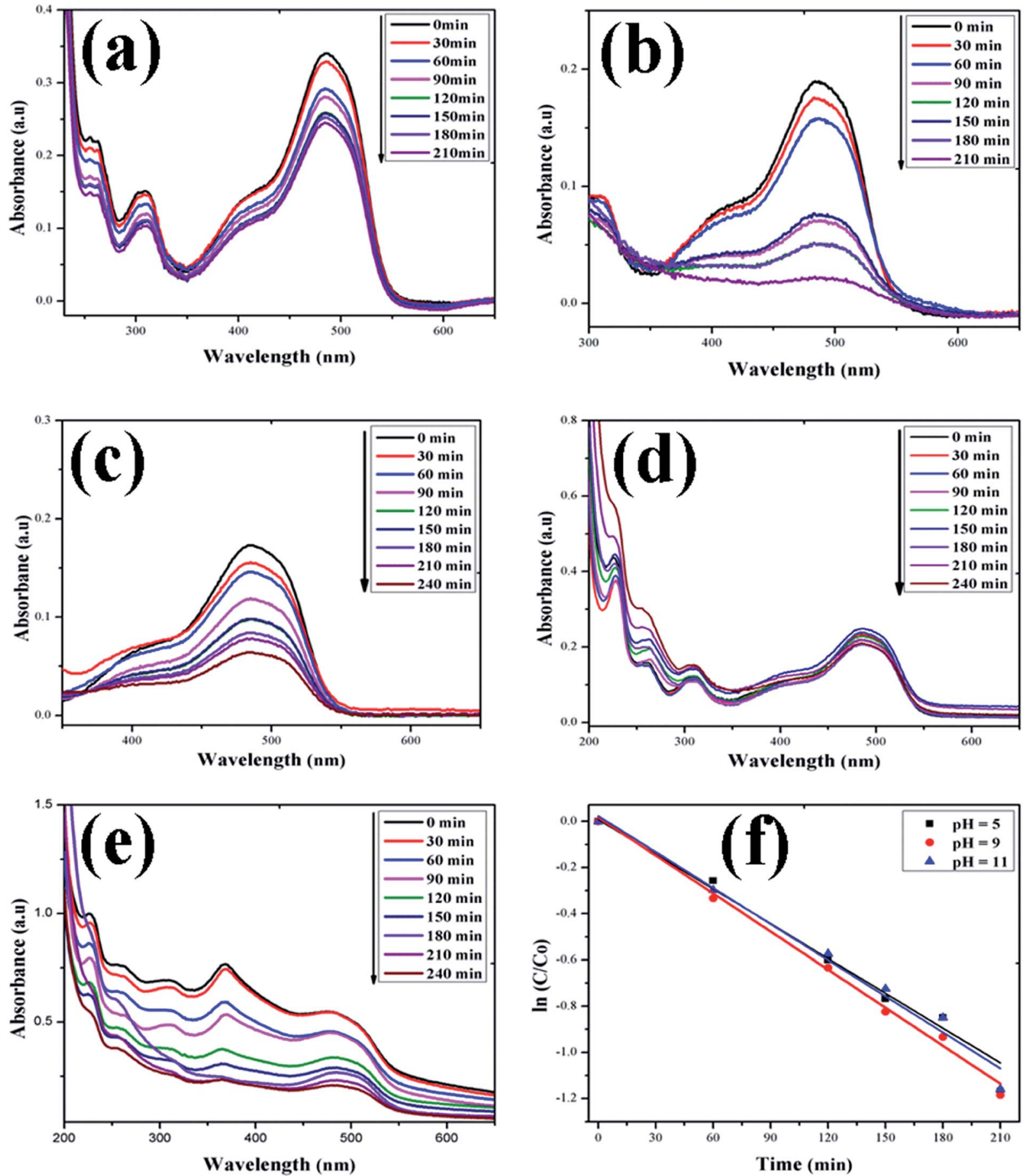

Fig. 11 Time-dependent UV-Vis spectra of (a) Oll dye without $\mathrm{ZnO}$; (b) Oll dye $+\mathrm{H}_{2} \mathrm{O}_{2}$; (c) Oll dye $+\mathrm{ZnO}+\mathrm{H}_{2} \mathrm{O}_{2}$ at pH $=5$; (d) Oll dye $+\mathrm{ZnO}+$ $\mathrm{H}_{2} \mathrm{O}_{2}$ at $\mathrm{pH}=$ 9; (e) Oll dye $+\mathrm{ZnO}+\mathrm{H}_{2} \mathrm{O}_{2}$ at $\mathrm{pH}=$ 11. (f) First-order kinetic model of $\mathrm{RhB}$ at different $\mathrm{pH}$ values. 
$0.75 \mathrm{~g} \mathrm{l}^{-1}, 1 \mathrm{~g} \mathrm{l}^{-1}$ ), mainly due to an increase in the number of active sites on the photocatalyst surface. Moreover, organic dye degradation was found to be $\mathrm{pH}$ dependent and the highest percentage of dye degradation was observed for $\mathrm{MB}$ at $\mathrm{pH}=11$ (80\%), $\mathrm{RhB}$ at $\mathrm{pH}=9(95 \%)$ and OII at $\mathrm{pH}=5$ (66\%). However, in the absence of $\mathrm{ZnO}$ nanostructures, the three dyes degraded slowly. Increasing the $\mathrm{pH}$ value for the cationic dyes (MB and $\mathrm{RhB}$ ) increased their photocatalytic degradation, mainly due to the production of more populated hydroxyl ions on the surface of the photocatalyst under visible and near-UV photoirradiation. In contrast, increasing the $\mathrm{pH}$ value of the anionic dye (OII) decreased its photocatalytic degradation, due to fewer hydroxyl radical formations on the surface of the photocatalyst under visible and near-UV photoirradiation. Therefore, the $\mathrm{pH}$ of the dye solution played a major role in the formation of stable dye-ZnO nanostructure complexes. The optimized $\mathrm{pH}$ values for the photodegradation of MB, RhB and OII were 11, 9 and 5, respectively. Increasing the time of contact between the photocatalyst ( $\mathrm{ZnO}$ nanostructures) and organic dye facilitated photodegradation of all organic dyes under visible and near-UV photoirradiation. The photodegradation of all the three organic dyes followed the decreasing order of: organic dye $+\mathrm{ZnO} \mathrm{NS}+$ $\mathrm{H}_{2} \mathrm{O}_{2}>$ organic dye $+\mathrm{ZnO} \mathrm{NS}>$ organic dye alone.

Reports show that green-synthesized ZnO NPs have been used in different applications such as photocatalysis for the removal of organic dye pollutants ${ }^{41,53-55}$ and as a bactericide. ${ }^{41,54,56-58}$ In the present work, the photocatalytic degradation of RhB under near-UV and visible irradiation using the assynthesized ZnO nanostructures showed 95\% degradation at $\mathrm{pH}=9$, and a similar result has been reported by Nagaraja et $a l .{ }^{59}$ It is better to use combined UV and visible irradiation rather than only UV light for the catalytic degradation of organic dye pollutants, since UV radiation can be dangerous. Dolichos lablab-capped ZnO nanostructures photocatalytically degraded $\mathrm{MB}, \mathrm{RhB}$ and OII dyes better than commercial ZnO NPs, which degrade MO, MB and RhB dyes by $68.1 \%, 75.5 \%$ and $65.7 \%$, respectively, under UV irradiation. ${ }^{60}$ Under UV irradiation, protein-capped $\mathrm{ZnO}$ NPs degrade $\mathrm{MB}$ dye at a reaction rate $(k)$ of $3.27 \times 10^{-3} \mathrm{~s}^{-1},{ }^{19}$ while in the present study, MB dye was degraded at a reaction rate of $9.14 \times 10^{-3} \min ^{-1}\left(1.52 \times 10^{-4}\right.$
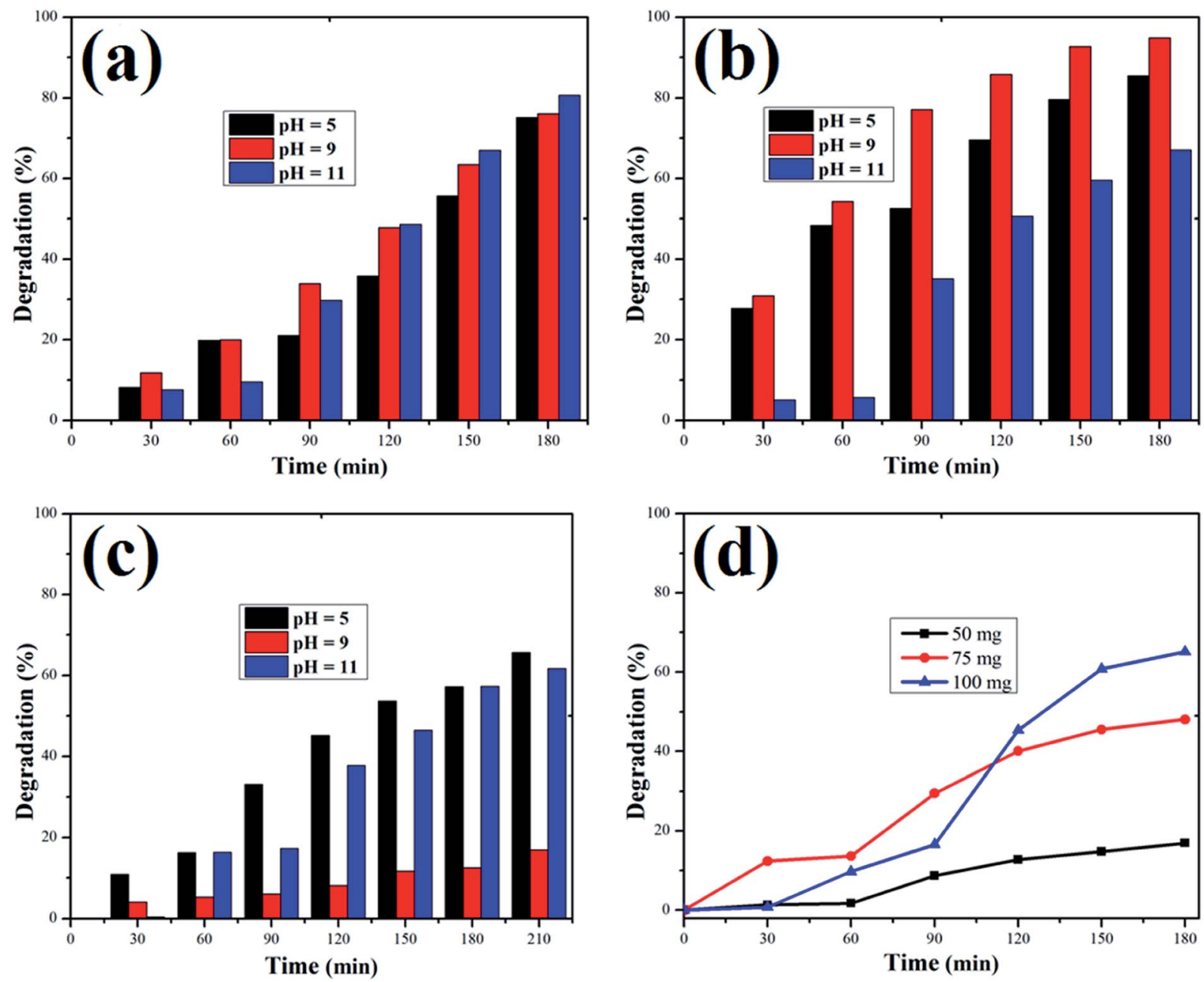

Fig. 12 Percentage of dye degradation versus time at pH 5, 9 and 11 for (a) Methylene blue, (b) rhodamine B., and (c) Orange II dye solutions. (d) Effect of catalyst dose on Methylene blue degradation. 

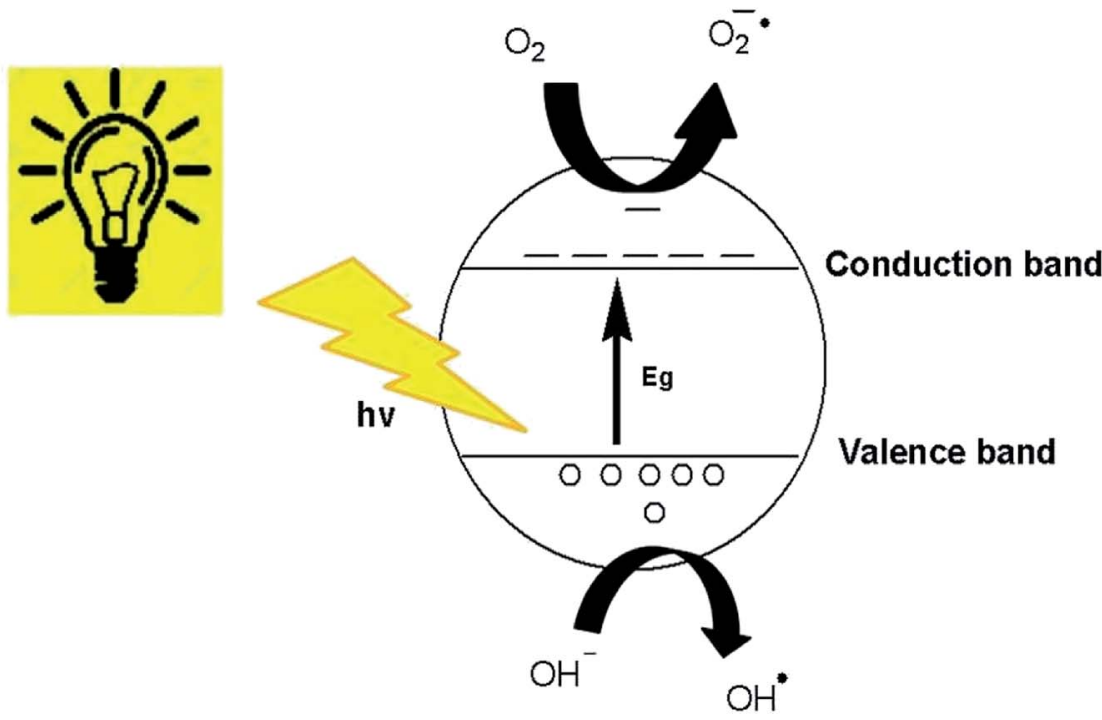

Fig. 13 Photocatalytic mechanism of $\mathrm{ZnO}$ nanostructures.

$\mathrm{s}^{-1}$ ), indicating that the rate of degradation is faster in the present study.

Generally, it can be concluded that the large surface area to volume ratio and large number of active sites on the $\mathrm{ZnO}$ nanostructures, where the photogenerated charge carriers are able to interact with the adsorbed organic dyes to form hydroxyl or superoxide radicals, facilitated the decolorization of organic dye molecules to $\mathrm{CO}_{2}$ and water. ${ }^{61}$ The degradation of dyes in this study occurred due to the photocatalytic process and dye sensitization. ${ }^{62}$ The schematic diagram of the photocatalytic mechanism over the surface of the $\mathrm{ZnO}$ nanostructures is presented in Fig. 13..$^{49,63}$ Organic dye degradation is caused by the photogeneration of hole-electron pairs between the valence and conduction bands. Photogenerated $\mathrm{h}^{+}$(hole) in the valence band reacts with either $\mathrm{H}_{2} \mathrm{O}$ or $\mathrm{OH}^{-}$to produce the $\mathrm{OH}^{*}$ radical. ${ }^{64}$ Aside from $\mathrm{OH}^{-}$, various species involved in the degradation mechanism are $\mathrm{O}_{2}{ }^{\cdot-}$ and $\mathrm{HO}_{2}{ }^{\cdot 65}$

$$
\begin{gathered}
\mathrm{h}^{+}+\mathrm{H}_{2} \mathrm{O} \rightarrow \mathrm{OH}^{\cdot}+\mathrm{H}^{+} \\
\mathrm{h}^{+}+\mathrm{OH}^{-} \rightarrow \mathrm{OH}^{\cdot}
\end{gathered}
$$

On the other hand, $\mathrm{e}^{-}$in the conduction band reacts with adsorbed $\mathrm{O}_{2}$ on the $\mathrm{ZnO}$ nanostructure surface to generate $\mathrm{O}_{2}{ }^{--}$ and then $\mathrm{OH}^{*}$ radicals. ${ }^{66}$

$$
\begin{gathered}
\mathrm{e}^{-}+\mathrm{O}_{2} \rightarrow \mathrm{O}_{2}^{\cdot-} \\
2 \mathrm{O}_{2}^{\cdot-}+\mathrm{H}^{+} \rightarrow \mathrm{HO}_{2}^{\cdot}+\mathrm{O}_{2}^{\cdot-} \\
2 \mathrm{HO}_{2}^{\cdot} \rightarrow \mathrm{H}_{2} \mathrm{O}_{2}+\mathrm{O}_{2} \\
\mathrm{H}_{2} \mathrm{O}_{2}+\mathrm{e}^{-} \rightarrow \mathrm{OH}^{\cdot}+\mathrm{OH}^{-} \\
\mathrm{H}_{2} \mathrm{O}_{2}+\mathrm{h}^{+} \rightarrow 2 \mathrm{OH}^{\cdot}
\end{gathered}
$$

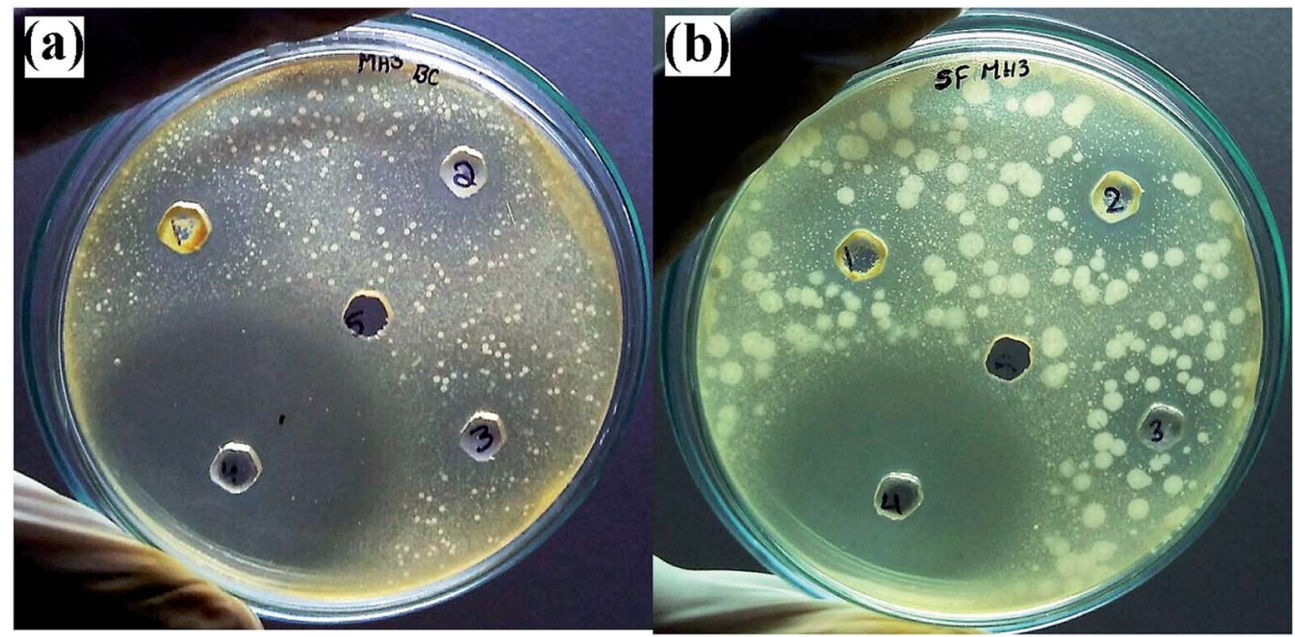

Fig. 14 Antimicrobial activities of synthesized ZnO nanostructures against (a) Bacillus pumilus, and (b) Sphingomonas paucimobilis. 
Table 3 Zone of inhibition of $\mathrm{ZnO}$ nanostructures against pathogens ${ }^{a}$

\begin{tabular}{|c|c|c|c|c|c|c|}
\hline \multirow[b]{2}{*}{ S. no. } & \multirow[b]{2}{*}{ Pathogens } & \multicolumn{3}{|c|}{$\begin{array}{l}\text { Concentration of } \mathrm{ZnO} \\
\text { nanostructures }\left(\mathrm{mg} \mathrm{ml}^{-1}\right)\end{array}$} & \multirow{2}{*}{$\frac{\text { Standard (Ciprofloxacin) }}{5 \mu \mathrm{g} / \mathrm{ml}}$} & \multirow[b]{2}{*}{ Control (DMSO) } \\
\hline & & 2.5 & 5.0 & 10.0 & & \\
\hline 1 & Bacillus pumilus & $12 \mathrm{~mm}$ & $18 \mathrm{~mm}$ & $15 \mathrm{~mm}$ & $40 \mathrm{~mm}$ & NA \\
\hline 2 & Sphingonomas paucimobilis & $15 \mathrm{~mm}$ & $20 \mathrm{~mm}$ & $15 \mathrm{~mm}$ & $40 \mathrm{~mm}$ & NA \\
\hline
\end{tabular}

Organic dye degradation or decolorization in the presence of the most reactive radicals can be generalized as follows.

$$
\text { Dye }+\left(\mathrm{O}_{2}{ }^{--} \text {or } \mathrm{OH}^{\cdot} \text { or } \mathrm{HO}_{2}{ }^{\cdot}\right) \rightarrow \text { intermediate }+ \text { products }
$$

\section{Antibacterial activity of $\mathrm{ZnO}$ nanostructures}

The antimicrobial activity of $\mathrm{ZnO}$ nanostructures against standard strains of Gram-positive (Bacillus pumilus) and Gramnegative (Sphingomonas paucimobilis) bacteria is shown in Fig. 14 and Table 3. A higher zone of inhibition was observed in Sphingomonas paucimobilis with a zone of inhibition of $20 \mathrm{~mm}$, whereas the inhibition zone in Bacillus pumilus was $18 \mathrm{~mm}$ at $5.0 \mathrm{mg} \mathrm{ml}{ }^{-1} \mathrm{ZnO}$ nanostructures, mainly due to the thick peptidoglycan layers in Gram-positive bacteria. However, in the negative control group (DMSO), no zone of inhibition was observed, whereas a standard (Ciprofloxacin) zone of inhibition of $40 \mathrm{~mm}$ was observed for both types of bacteria.

Hexagonal wurtzite structured ZnO NPs biosynthesized using the Pichia kudriavzevii yeast strain has previously been reported to show antimicrobial activity against both Grampositive bacteria and Gram-negative bacteria, in which the zone of inhibition against B. subtilis (Gram-positive) was 9 mm. ${ }^{67}$ However, our green-synthesized $\mathrm{ZnO}$ nanostructures using Dolichos lablab L extract showed a zone of inhibition of $18 \mathrm{~mm}$ against Bacillus pumilus, which is also Gram-positive. The zone of inhibition of our green-synthesized $\mathrm{ZnO}$ nanostructures against Sphingomonas paucimobilis showed a better zone of inhibition than that reported by Safawo et al. ${ }^{\mathbf{5 8}}$.

\section{Conclusions}

Hexagonal wurtzite and irregularly shaped $\mathrm{ZnO}$ nanostructures were synthesized using aqueous leaf extract of Dolichos lablab L. via a green synthesis approach. The phytoconstituents such as phenolic compounds and proteins present in the Dolichos lablab L. were found to be responsible for the formation and capping of $\mathrm{ZnO}$ nanostructures. The formation of the $\mathrm{ZnO}$ nanostructures was confirmed by UV-Vis, UV-DRS, FT-IR, XRD, FE-SEM supported with EDX and TEM. UV-DRS revealed a band gap of $3.4 \mathrm{eV}$, indicating the semiconducting behavior of the $\mathrm{ZnO}$ nanostructures. Using $\mathrm{ZnO}$ nanostructures as a photocatalyst for the degradation of organic dyes, MB, RhB and OII were photodegraded by 80,95 , and $66 \%$, respectively. The antimicrobial activity of the $\mathrm{ZnO}$ nanostructures using the agar well diffusion method against Bacillus pumilus and Sphingomonas paucimobilis showed zones of inhibition of $18 \mathrm{~mm}$ and 20 $\mathrm{mm}$, respectively. Hence, the $\mathrm{ZnO}$ nanostructures could be used as a semiconductor photocatalyst as well as a bactericide for pathogenic bacteria during wastewater treatment.

\section{Conflicts of interest}

The authors agree there are no conflicts to declare.

\section{Acknowledgements}

The authors acknowledge UGC-SAP-DRS-I (no. F.540/18/DRS-I/ 2016) and DST-FIST (5R/FIST/CSI-241/2012(C)), Department of Inorganic and Analytical Chemistry, Andhra University. Mebrahtu Hagos Kahsay, Aschalew Tadesse and Neway Belachew would like to acknowledge the Ministry of Science and Higher Education, Federal Democratic Republic of Ethiopia, for financial support.

\section{References}

1 M. Rafatullah, O. Sulaiman, R. Hashim and A. Ahmad, J. Hazard. Mater., 2010, 177, 70-80.

2 B. Ramaraju, P. M. K. Reddy and C. Subrahmanyam, Environ. Prog. Sustainable Energy, 2013, 33, 38-46.

3 S. S. Vieira, Z. M. Magriotis, N. A. V. Santos, M. das G. Cardoso and A. A. Saczk, Chem. Eng. J., 2012, 183, 152-161.

4 H. A. Mekkawy, M. O. Ali and A. M. El-Zawahry, Toxicol. Lett., 1998, 95, 155.

5 D. A. Oxspring, G. McMullan, W. Franklyn Smyth and R. Marchant, Biotechnol. Lett., 1996, 18, 527-530.

6 S. D. Richardson, C. S. Willson and K. A. Rusch, Ground Water, 2004, 42, 678-688.

7 J. Rochat, P. Demenge and J. C. Rerat, Toxicol. Eur. Res., 1978, 1, 23-26.

8 A. K. Dutta, S. K. Maji and B. Adhikary, Mater. Res. Bull., 2014, 49, 28-34.

9 M. Nageeb, Adsorption Technique for the Removal of Organic Pollutants from Water and Wastewater, in Organic Pollutants-Monitoring, Risk and Treatment, 2013. 
10 T. Dey, Nanotechnology for Water Purification, UniversalPublishers, 2012.

11 A. Umar and Y. B. Hahn, Metal oxide nanostructures and their applications: ZnO nanostructures and nanodevices, American Scientific Publishers (ASP), Los Angeles, USA, 2010.

12 Z. Fan and J. G. Lu, Int. J. High Speed Electron. Syst., 2006, 16, 883-896.

13 A. Sirelkhatim, S. Mahmud, A. Seeni, N. H. M. Kaus, L. C. Ann, S. K. M. Bakhori, H. Hasan and D. Mohamad, Nano-Micro Lett., 2015, 7, 219-242.

14 K. Vimala, S. Sundarraj, M. Paulpandi, S. Vengatesan and S. Kannan, Process Biochem., 2014, 49, 160-172.

15 P. Venkatachalam, M. Jayaraj, R. Manikandan, N. Geetha, E. R. Rene, N. C. Sharma and S. V. Sahi, Plant Physiol. Biochem., 2017, 110, 59-69.

16 A. S. H. Hameed, C. Karthikeyan, A. P. Ahamed, N. Thajuddin, N. S. Alharbi, S. A. Alharbi and G. Ravi, Sci. Rep., 2016, 6, 24312.

17 F. Movahedi, H. Masrouri and M. Z. Kassaee, J. Mol. Catal. A: Chem., 2014, 395, 52-57.

18 L. Martinkova, B. Uhnakova, M. Patek, J. Nesvera and V. Kren, Environ. Int., 2009, 35, 162-177.

19 N. Jain, A. Bhargava and J. Panwar, Chem. Eng. J., 2014, 243, 549-555.

20 J. W. Rasmussen, E. Martinez, P. Louka and D. G. Wingett, Expert Opin. Drug Delivery, 2010, 7, 1063-1077.

21 E. Selvarajan and V. Mohanasrinivasan, Biosynthesis and characterization of $\mathrm{ZnO}$ nanoparticles using Lactobacillus plantarum VITES07, Mater. Lett., 2013, 112, 180-182.

22 R. Dobrucka and J. Długaszewska, Biosynthesis and antibacterial activity of $\mathrm{ZnO}$ nanoparticles using Trifolium pratense flower extract, Saudi J. Biol. Sci., 2016, 23(4), 517523.

23 S. Singh, M. Joshi, P. Panthari, B. Malhotra, A. C. Kharkwal and $\mathrm{H}$. Kharkwal, Citrulline rich structurally stable zinc oxide nanostructures for superior photo catalytic and optoelectronic applications: a green synthesis approach, Nano-Struct. Nano-Objects, 2017, 11, 1-6.

24 A. M. Awwad, B. Albiss and A. L. Ahmad, Green Synthesis, Characterization And Optical Properties of Zinc Oxide Nanosheets Using Olea Europea Leaf Extract, Adv. Mater. Lett., 2014, 5(9), 520-524.

25 G. Sangeetha, S. Rajeshwari and R. Venckatesh, Green synthesis of zinc oxide nanoparticles by aloe barbadensis miller leaf extract: Structure and optical properties, Mater. Res. Bull., 2011, 46(12), 2560-2566.

26 P. Rajiv, S. Rajeshwari and R. Venckatesh, Bio-Fabrication of zinc oxide nanoparticles using leaf extract of Parthenium hysterophorus $L$. and its size-dependent antifungal activity against plant fungal pathogens, Spectrochim. Acta, Part A, 2013, 112, 384-387.

27 P. C. Nagajyothi, T. N. M. An, T. V. M. Sreekanth, J.-I. Lee, D. J. Lee and K. D. Lee, Green route biosynthesis: Characterization and catalytic activity of $\mathrm{ZnO}$ nanoparticles, Mater. Lett., 2013, 108, 160-163.

28 R. P. Singh, V. K. Shukla, R. S. Yadav, P. K. Sharma, P. K. Singh and A. C. Pandey, Biological Approach Of Zinc
Oxide Nanoparticles Formation And Its Characterization, Adv. Mater. Lett., 2011, 2(4), 313-317.

29 S. Nagarajan and K. Arumugam Kuppusamy, Extracellular synthesis of zinc oxide nanoparticle using seaweeds of gulf of Mannar, India, J. Nanobiotechnol., 2013, 11, 39.

30 T. Bhuyan, K. Mishra, M. Khanuja, R. Prasad and A. Varma, Biosynthesis of zinc oxide nanoparticles from Azadirachta indica for antibacterial and photocatalytic applications, Mater. Sci. Semicond. Process., 2015, 32, 55-61.

31 A. C. Janaki, A. Chinnammal Janaki, E. Sailatha and S. Gunasekaran, Synthesis, characteristics and antimicrobial activity of $\mathrm{ZnO}$ nanoparticles, Spectrochim. Acta, Part A, 2015, 144, 17-22.

32 S. Kalyanasundaram and M. Jeevan Prakash, Biosynthesis and Characterization of Titanium Dioxide Nanoparticles Using Pithecellobium Dulce and Lagenaria Siceraria Aqueous Leaf Extract and Screening their Free Radical Scavenging and Antibacterial Properties, Int. Lett. Chem., Phys. Astron., 2015, 50, 80-95.

33 M. Ramesh, M. Anbuvannan and G. Viruthagiri, Green synthesis of $\mathrm{ZnO}$ nanoparticles using Solanum nigrum leaf extract and their antibacterial activity, Spectrochim. Acta, Part A, 2015, 136, 864-870.

34 R. K. Deka and C. R. Sarkar, Nutrient composition and antinutritional factors of Dolichos lablab L. seeds, Food Chem., 1990, 38(4), 239-246.

35 C.-F. Chau, P. C.-K. Cheung and Y.-S. Wong, Chemical composition of three underutilized legume seeds grown in China, Food Chem., 1998, 61(4), 505-509.

36 V. Maheshu, D. T. Priyadarsini and J. M. Sasikumar, Effects of processing conditions on the stability of polyphenolic contents and antioxidant capacity of Dolichos lablab L, $J$. Food Sci. Technol., 2011, 50(4), 731-738.

37 B. Bonev, J. Hooper and J. Parisot, Principles of assessing bacterial susceptibility to antibiotics using the agar diffusion method, J. Antimicrob. Chemother., 2008, 61(6), 1295-1301.

38 K. H. Wong and P. C. K. Cheung, Nutritional assessment of three Chinese indigenous legumes in growing rats, Nutr. Res., 1998, 18(9), 1573-1580.

39 K. O. Soetan, Comparative evaluation of phytochemicals in the raw and aqueous crude extracts from seeds of three Lablab purpureus varieties, Afr. J. Plant Sci., 2012, 6(15), 410-415.

40 A. Mang, K. Reimann and S. Rübenacke, Band gaps, crystalfield splitting, spin-orbit coupling, and exciton binding energies in $\mathrm{ZnO}$ under hydrostatic pressure, Solid State Commun., 1995, 94(4), 251-254.

41 S. A. Khan, F. Noreen, S. Kanwal, A. Iqbal and G. Hussain, Green synthesis of $\mathrm{ZnO}$ and $\mathrm{Cu}$-doped $\mathrm{ZnO}$ nanoparticles from leaf extracts of Abutilon indicum, Clerodendrum infortunatum, Clerodendrum inerme and investigation of their biological and photocatalytic activities, Mater. Sci. Eng., C, 2018, 82, 46-59.

42 K. Ravichandran, K. Nithiyadevi, B. Sakthivel, T. Arun, E. Sindhuja and G. Muruganandam, Synthesis of ZnO:Co/ rGO nanocomposites for enhanced photocatalytic and 
antibacterial activities, Ceram. Int., 2016, 42(15), 1753917550.

43 B. Gokulakumar and R. Narayanaswamy, Fourier transforminfrared spectra (FT-IR) analysis of root rot disease in sesame (Sesamum indicum), Rom. J. Biophys., 2008, 18, 217-223.

44 C. G. Udayabhanu, G. Nagaraju, H. Nagabhushana, D. Suresh, C. Anupama, G. K. Raghu and S. C. Sharma, Vitis labrusca skin extract assisted green synthesis of $\mathrm{ZnO}$ super structures for multifunctional applications, Ceram. Int., 2017, 43(15), 11656-11667.

45 Z. Tao, X. Yu, J. Liu, L. Yang and S. Yang, A facile synthesis and photoluminescence of porous S-doped $\mathrm{ZnO}$ architectures, J. Alloys Compd., 2008, 459(1-2), 395-398.

46 B. D. Cullity Elements of X-ray Diffraction; Addison Wesley Publishing Company, 1978.

47 P. Jamdagni, P. Khatri and J. S. Rana, Green synthesis of zinc oxide nanoparticles using flower extract of Nyctanthes arbortristis and their antifungal activity, J. King Saud Univ., Sci., 2018, 30, 168-175.

48 M.-K. Liang, M. J. Limo, A. Sola-Rabada, M. J. Roe and C. C. Perry, New Insights into the Mechanism of $\mathrm{ZnO}$ Formation from Aqueous Solutions of Zinc Acetate and Zinc Nitrate, Chem. Mater., 2014, 26(14), 4119-4129.

49 R. M. Tripathi, A. S. Bhadwal, R. K. Gupta, P. Singh, A. Shrivastav and B. R. Shrivastav, ZnO nanoflowers: novel biogenic synthesis and enhanced photocatalytic activity, $J$. Photochem. Photobiol., B, 2014, 141, 288-295.

50 R. M. Felder and R. W. Rousseau, Elementary Principles of Chemical Processes, Integrated Media and Study Tools, with Student Workbook, Wiley, 3rd edn, 2005.

51 H. Scott Fogler, Elements of chemical reaction engineering, Chem. Eng. Sci., 1987, 42(10), 2493.

52 N. Rana, S. Chand and A. K. Gathania, Green synthesis of zinc oxide nano-sized spherical particles using Terminalia chebula fruits extract for their photocatalytic applications, Int. Nano Lett., 2016, 6, 91-98.

53 O. J. Nava, C. A. Soto-Robles, C. M. Gómez-Gutiérrez, A. R. Vilchis-Nestor, A. Castro-Beltrán, A. Olivas and P. A. Luque, J. Mol. Struct., 2017, 1147, 1-6.

54 N. Kumar, A. S. Bhadwal, M. Garg, R. Sharma, S. Singh and B. Mizaikoff, Anal. Methods, 2017, 9, 4776-4782.

55 G. Madhumitha, G. Elango and S. M. Roopan, Appl. Microbiol. Biotechnol., 2016, 100, 571-581.
56 A. Fouda, S. El-Din Hassan, S. S. Salem and T. I. Shaheen, Microb. Pathog., 2018, 125, 252-261.

57 K. Nithya and S. Kalyanasundharam, Open Nanosci. J., 2019, 4, 100024.

58 T. Safawo, B. V. Sandeep, S. Pola and A. Tadesse, Open Nanosci. J., 2018, 3, 56-63.

59 R. Nagaraja, N. Kottam, C. R. Girija and B. M. Nagabhushana, Powder Technol., 2012, 215-216, 91-97.

60 B. Rodríguez-Cabo, I. Rodríguez-Palmeiro, R. Corchero, R. Rodil, E. Rodil, A. Arce and A. Soto, Water Sci. Technol., 2017, 75, 128-140.

61 A. Pimentel, J. Rodrigues, P. Duarte, D. Nunes, F. M. Costa, T. Monteiro, R. Martins and E. Fortunato, Effect of solvents on ZnO nanostructures synthesized by solvothermal method assisted by microwave radiation: a photocatalytic study, J. Mater. Sci., 2015, 50(17), 5777-5787.

62 N. Barbero and D. Vione, Why Dyes Should Not Be Used to Test the Photocatalytic Activity of Semiconductor Oxides, Environ. Sci. Technol., 2016, 50(5), 2130-2131.

63 A. P. Rivera, K. Tanaka and T. Hisanaga, Photocatalytic degradation of pollutant over $\mathrm{TiO}_{2}$ in different crystal structures, Appl. Catal., B, 1993, 3(1), 37-44.

64 J. Herrmann, H. Tahiri, Y. Aitichou, G. Lassaletta, A. Gonzalezelipe and A. Fernandez, Characterization and photocatalytic activity in aqueous medium of $\mathrm{TiO}_{2}$ and $\mathrm{Ag}-$ $\mathrm{TiO}_{2}$ coatings on quartz, Appl. Catal., B, 1997, 13(3-4), 219228.

65 S.-M. Lam, J.-C. Sin, A. Z. Abdullah and A. R. Mohamed, Degradation of wastewaters containing organic dyes photocatalysed by zinc oxide: a review, Desalin. Water Treat., 2012, 41(1-3), 131-169.

66 K. Vignesh, A. Suganthi, M. Rajarajan and S. A. Sara, Photocatalytic activity of AgI sensitized $\mathrm{ZnO}$ nanoparticles under visible light irradiation, Powder Technol., 2012, 224, 331-337.

67 A. B. Moghaddam, M. Moniri, S. Azizi, R. A. Rahim, A. B. Ariff, W. Z. Saad, F. Namvar and M. Navaderi, Biosynthesis of ZnO Nanoparticles by a New Pichia kudriavzevii Yeast Strain and Evaluation of Their Antimicrobial and Antioxidant Activities, Molecules, 2017, 22, 872 . 